\section{BIOCATÁLISIS Y BIOTECNOLOGÍA}

\author{
Miguel Arroyo \\ Universidad Complutense de Madrid \\ Carmen Acebal \\ Universidad Complutense de Madrid \\ Isabel de la Mata \\ Universidad Complutense de Madrid \\ idlmata@ucm.es
}

Cómo citar este artículo/Citation: Arroyo, M.; Acebal, C. y Mata, I. de la (2014). "Biocatálisis y biotecnología". Arbor, 190 (768): a156. doi: http://dx.doi.org/10.3989/ arbor.2014.768n4010

Recibido: 9 junio 2014. Aceptado: 14 julio 2014.

RESUMEN: La Biocatálisis ha surgido como un área de gran riqueza dentro de la Biotecnología, y ha permitido la aplicación de las enzimas en un amplio número de industrias dedicadas a la fabricación de fármacos y otros compuestos químicos, así como alimentos o biocombustibles. Este sorprendente desarroIlo de la Biocatálisis se debe a nuevas tecnologías como la bioinformática, el cribado de alta resolución, la evolución dirigida, así como otras técnicas arraigadas como la inmovilización de enzimas y la ingeniería de proteínas o del medio de reacción. La fabricación sostenible de productos de consumo es uno de los objetivos principales de la Biocatálisis, y supondrá muchos desafíos y oportunidades en el futuro. En este artículo, se han revisado algunos de los principales métodos empleados en tecnología enzimática, así como varios ejemplos de aplicaciones de las enzimas en la industria. Finalmente, se indica un breve comentario sobre la situación actual de los grupos de investigación y empresas dedicados a la Biocatálisis en España.

PALABRAS CLAVE: Biocatálisis; enzimas; inmovilización; tecnología enzimática; síntesis; industria.

\section{BIOCATALYSIS AND BIOTECHNOLOGY}

Copyright: (c) 2014 CSIC. Este es un artículo de acceso abierto distribuido bajo los términos de la licencia Creative Commons Attribution-Non Commercial (by-nc) Spain 3.0.

ABSTRACT: Biocatalysis has emerged as a rich field within Biotechnology, enabling the application of enzymes in a wide range of industries ranging from pharmaceuticals and fine chemicals to food and energy. This striking development of Biocatalysis is due to novel technologies such as bioinformatics, high-throughput screening (HTS), directed evolution, as well as other well-established techniques such as enzyme immobilization and protein engineering or medium engineering. Sustainable manufacturing is a major driver of Biocatalysis, which will provide many real challenges and opportunities for the future. In this article, some of the main methods in enzyme technology have been reviewed, as well as several biotechnological applications of enzymes in industry. Finally, a brief overview of the situation of Biocatalysis in both Spanish academia and industry has also been reported.

KEYWORDS: Biocatalysis; enzymes; immobilization; enzyme technology; synthesis; industry. 


\section{INTRODUCCIÓN}

Durante siglos el hombre ha utilizado los microorganismos en su beneficio sin saber que las transformaciones obtenidas se debían a la función de determinadas enzimas presentes en los organismos utilizados. Así, antes de que se conocieran las bases bioquímicas de los procesos biocatalizados, la capacidad catalítica de las enzimas presentes en los microorganismos como la levadura Saccharomyces cerevisiae o las bacterias lácticas se han utilizado desde hace siglos en la producción de alimentos como el vino, la cerveza, el queso, el vinagre o el pan. Aunque el término enzima fue acuñado por primera vez por Küne en 1876, el conocimiento profundo de las enzimas, su estructura, cinética, relación estructura-función, no se ha alcanzado hasta años recientes, cuando la investigación de las enzimas adquiere una nueva fase gracias a los conocimientos aportados de distintas disciplinas como son la química de proteínas, la biofísica y la biología molecular. Esto ha hecho avanzar en el conocimiento del potencial tecnológico de estas biomoléculas. Respecto a la utilización industrial de los biocatalizadores, tiene más de un siglo de historia. En 1875, en Copenhague, Christian Hansen crea una compañía que fue la primera en usar industrialmente, para la fabricación del queso, una preparación enzimática estandarizada llamada RENNET, que es una mezcla de quimosina (o renina) y pepsina, obtenida con una extracción con sal de la cuarta cavidad estomacal de terneras lactantes (método que se sigue utilizando en la actualidad. Otro hito importante en la utilización de las enzimas a nivel industrial tuvo lugar con el descubrimiento del químico alemán Otto Röhm en 1913 de la eficacia de la tripsina pancreática en la eliminación de manchas de origen proteico como sangre, leche etc., y que fueron los comienzos de la utilización de las enzimas en los detergentes.

En la actualidad son numerosos los procesos biotecnológicos que se llevan a cabo mediante la utilización de células o de sus enzimas aisladas, siendo un campo con grandes perspectivas de futuro.

El término Biocatálisis se refiere a la utilización de células o sus enzimas aisladas para catalizar reacciones o transformaciones que conducen a la obtención de compuestos de interés, que satisfacen numerosas necesidades humanas. La Biocatálisis se encuentra enmarcada en la denominada Biotecnología Blanca, subsector de la Biotecnología con importantes perspectivas de crecimiento, clave para el desarrollo de la denominada bioeconomía.

La utilización de células o enzimas ha demostrado su eficacia en la síntesis de fármacos, herbicidas, insecticidas y otros productos químicos, en la producción de biocombustibles alternativos al petróleo, o en la industria textil y de detergentes, entre otros muchos ejemplos (Tabla 1). Ello se debe a que representan una alternativa más eficiente y a la vez más ecológica a la química sintética tradicional, ya que los procesos que catalizan transcurren a través de reacciones en medios más respetuosos con el medio ambiente y bajo condiciones de $\mathrm{pH}$ y temperatura suaves con mayores rendimientos ya que son procesos regio y estereoselectivos y con menor coste económico. No es de extrañar que el negocio de las enzimas haya crecido incesantemente en los últimos años, y las expectativas indican que el mercado global se puede situar en cifras superiores a los 4400 millones de dólares en el año 2015.

Tabla 1. Aplicaciones de la Biocatálisis en distintos sectores productivos

\begin{tabular}{|c|c|}
\hline $\begin{array}{l}\text { SECTOR SANITARIO-FARMACÉUTICO } \\
\text { - Enzimas para diagnóstico } \\
\text { - Enzimas de uso terapéutico } \\
\text { - Síntesis de intermedios y compuestos } \\
\text { químicos de interés farmacéutico }\end{array}$ & $\begin{array}{l}\text { SECTOR AGROALIMENTARIO } \\
\text { - Aromas, edulcorantes y aditivos } \\
\text { alimentarios } \\
\text { - Aminoácidos y otras moléculas } \\
\text { nutritivas } \\
\text { - Enzimas para queserías y productos } \\
\text { lácteos dietéticos (sin lactosa) } \\
\text { - Insecticidas y herbicidas }\end{array}$ \\
\hline $\begin{array}{l}\text { SECTOR MEDIOAMBIENTAL } \\
\text { - Biorremediación } \\
\text { - Obtención de plásticos } \\
\text { biodegradables } \\
\text { - Biocombustibles }\end{array}$ & $\begin{array}{l}\quad \text { PROCESOS INDUSTRIALES } \\
\text { - Detergentes } \\
\text { - Industria textil y peletera } \\
\text { - Síntesis de compuestos químicos }\end{array}$ \\
\hline
\end{tabular}


En general, el escalado industrial de cualquier proceso biocatalizado requiere actualmente de unas etapas previas que incluyen: (1) la selección de la enzima más adecuada, (2) su producción, aislamiento y purificación, (3) su caracterización para determinar las condiciones idóneas para la catálisis enzimática, y finalmente, (4) su inmovilización con el fin de reducir los costes. Todas estas etapas se suelen agrupar bajo el término "ciclo biocatalítico" (Figura 1).

Asimismo, como ya se ha indicado, también son numerosos los procesos en los que se utilizan las células completas debido en la mayoría de los casos a la imposibilidad de obtener preparados enzimáticos estables.

\section{PRODUCCIÓN DE ENZIMAS PARA USO BIOTEC- NOLÓGICO}

Actualmente se calculan que existen 36 empresas biotecnológicas dedicadas a la producción de enzimas que se pueden clasificar en grandes compañías multinacionales productoras de enzimas de bajo coste y gran demanda (destacan la danesa Novozymes, la holandesa DSM y la americana Genzyme), y pequeñas empresas dedicadas a la preparación de cantidades pequeñas de enzimas de elevado coste que se utilizan principalmente con fines analíticos, ingeniería genética o terapia enzimática (por ejemplo, la japonesa Amano, o la británica Biocatalysis Ltd.).

Hasta ahora, los microorganismos han sido la principal fuente de enzimas de aplicación industrial, ya que presentan numerosas ventajas técnicas y económicas en comparación con las enzimas de origen animal o vegetal. Por un lado, los microorganismos son una fuente muy versátil de enzimas, pudiéndose aislar nuevos microorganismos productores mediante cribado o "screening" a partir de distintas fuentes naturales y/o de colecciones tipo (ATCC, DSMZ, CECT, etc.). Más recientemente, mediante técnicas biotecnológicas como la metagenómica, es posible obtener enzimas nuevas y con capacidades catalíticas novedosas, sobre todo en aquellos casos en los que el microorganismo productor es difícil de crecer in vitro; y gracias a que cada vez es mayor el número de genomas secuenciados, mediante el denominado screening in silico es posible obtener nuevas enzimas no solo de microorganismos sino también de plantas y animales. Esto unido a que los microorganismos pueden ser modificados mediante ingeniería genética con el fin

Figura 1. Etapas en el escalado industrial de un proceso biocatalizado por enzimas

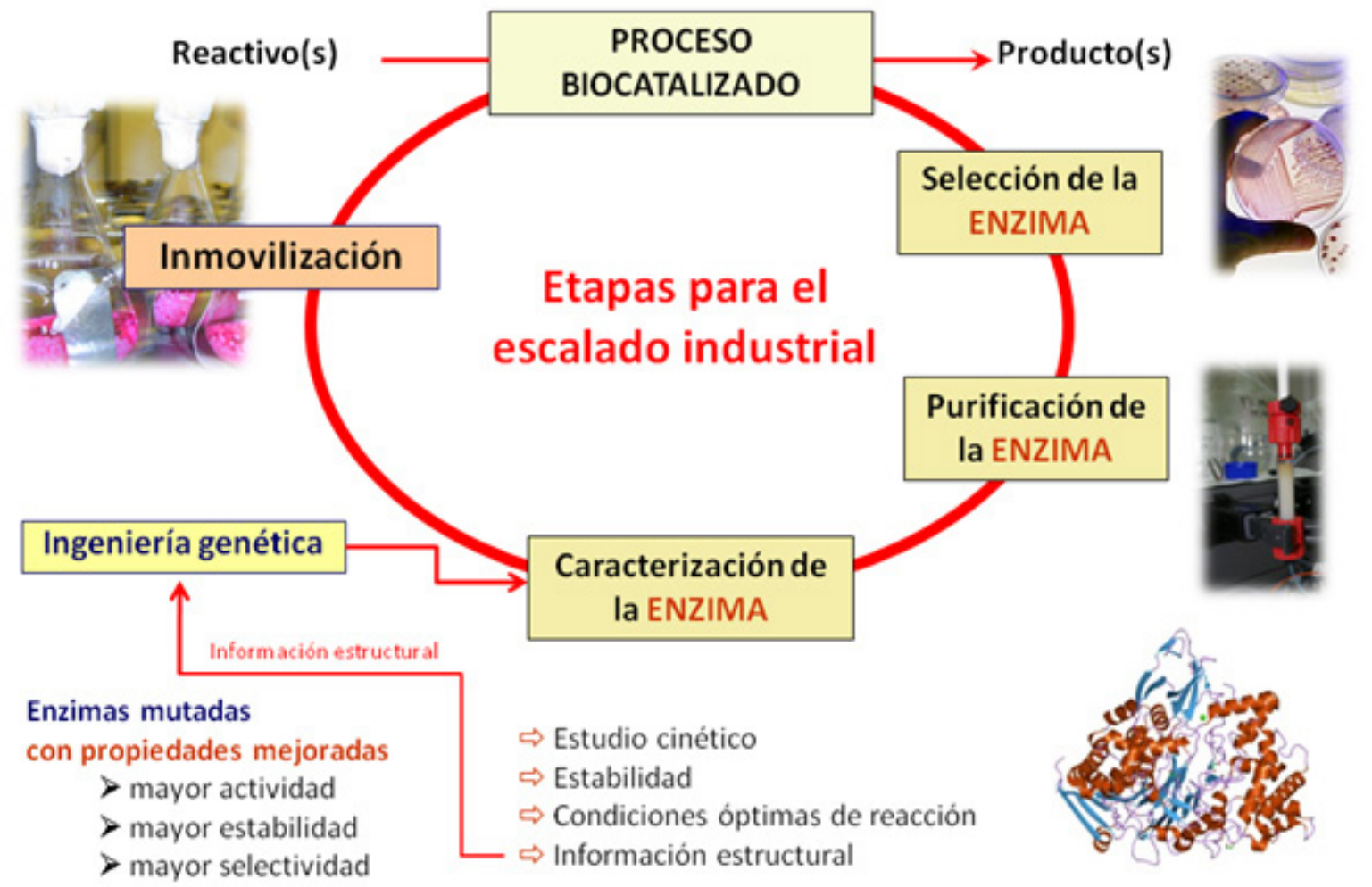


de producir mayor cantidad de enzima, ha hecho que cada vez sea mayor el número de enzimas disponibles para su aplicación en una gran variedad de campos. La purificación de las enzimas microbianas suele ser fácil, sobre todo si son extracelulares; en contraste con la extracción de enzimas de origen animal o vegetal que resulta más compleja, ya que requiere de etapas previas que incluyen el aislamiento de los tejidos, así como su homogeneización. A diferencia de las plantas y los animales, la producción de las enzimas microbianas requiere poca superficie, su rendimiento es predecible y no presenta oscilaciones, y su disponibilidad es continuada. Finalmente, los microorganismos tienen velocidades de crecimiento y de producción de enzimas muy altas, por lo que los procesos fermentativos son los más empleados en la producción de enzimas microbianas de uso biotecnológico. Dichos procesos pueden ser fermentaciones en superficie (o método "koji", muy empleado en países orientales), o cultivos sumergidos en biorreactores de hasta 100.000 litros de capacidad (más común en países occidentales), empleando medios de crecimiento baratos y eficaces. El escenario más sencillo y, por tanto más económico para una empresa, es la producción de una enzima microbiana extracelular a partir del medio de cultivo libre de células. Sin embargo, existen muchas enzimas intracelulares que requieren la ruptura celular, lo que complica el proceso de purificación (mayor número de proteínas a separar, aumento de la viscosidad del medio por liberación de los ácidos nucleicos, etc.). En muchas aplicaciones industriales, las preparaciones enzimáticas suelen estar parcialmente purificadas. No obstante, las enzimas utilizadas en pruebas diagnósticas o enzimas de uso terapéutico, deben tener el máximo grado de pureza (100\% puras a homogeneidad, y sin trazas de ácidos nucleicos ni compuestos pirógenos). En cualquier caso, se debe recurrir a los métodos de purificación convencionales como la cromatografía de proteínas, pero a escala industrial. Asimismo, durante los procesos industriales de purificación de enzimas, se suelen utilizar sistemas en continuo: de abrasión para romper células (v.g. Dynomill), de centrifugación para conseguir la separación de sobrenadantes y sedimentos (centrífugas de cestillo, de taza, cilíndricas, tubulares), de ultrafiltración para enriquecer o concentrar, o de diafiltración para dializar. Finalmente, la enzima purificada se puede vender como producto final en diferentes formatos: (1) liofilizadas, en el caso de enzimas de uso diagnóstico o enzimas terapéuticas, (2) disueltas en presencia de sulfato amónico que actúa como estabilizante; o (3) mezcladas con diferentes aditivos (sales, azúcares, ce- ras) en el caso de enzimas comercializadas en grandes cantidades, con la fin de facilitar el transporte y evitar reacciones alérgicas durante su manipulación.

\section{INMOVILIZACIÓN DE ENZIMAS}

Las enzimas presentan una serie de ventajas frente a los catalizadores inorgánicos tradicionales: (1) una elevada especificidad, estereoselectividad y regioespecificidad; y (2) una gran actividad a temperatura ambiente y presión atmosférica. A pesar de estas claras ventajas, el empleo de estos biocatalizadores no se ha generalizado en la industria, debido principalmente a: (1) su limitada estabilidad ya que son proteínas que se pueden desnaturalizar, y perder totalmente su actividad; y (2) la dificultad que entraña su separación de los sustratos y productos en el medio de reacción, lo que impide su reutilización. La inmovilización de enzimas ha logrado superar estos inconvenientes, y ha permitido que muchos procesos industriales biocatalizados sean rentables económicamente en la actualidad. En general, los métodos de inmovilización se suelen clasificar en dos grandes categorías: la retención física y la unión química. El atrapamiento de enzimas y la inclusión en membranas son los principales métodos de inmovilización por retención física, mientras que la unión de enzimas a soportes y el reticulado son los métodos por unión química más destacados. En resumen, el atrapamiento consiste en la retención física de la enzima en las cavidades interiores de una matriz sólida porosa, que puede ser un polímero sintético (v.g. geles de poliacrilamida, resinas de poliuretano, etc.) o natural (alginato, quitosano, agarosa, etc.). La microencapsulación es un método de retención física en el que las enzimas están rodeadas de membranas semipermeables, permitiendo exclusivamente el paso de moléculas de sustrato y producto, pero no de enzima. Dentro de los métodos por unión química, la unión de enzimas a soportes es el más utilizado y del que se dispone de mayor información. Se pueden utilizar una gran variedad de materiales (inorgánicos y orgánicos) como soportes de inmovilización, los cuales difieren en tamaño, densidad, porosidad y forma, aunque generalmente se comercializan en forma de cilindro, hojas, fibras, y más corrientemente en forma de esferas. El soporte elegido debe tener resistencia mecánica adecuada a las condiciones de operación, y ser fácilmente separable del medio líquido para que pueda ser reutilizado. Las enzimas se pueden unir a estos soportes mediante unión no covalente o unión covalente. Por un lado, la unión no covalente de una enzima a un determinado soporte se puede establecer mediante: (1) interacciones específicas (iónicas, 
hidrofóbicas, quelación), y (2) interacciones no específicas. Por otro lado, la unión covalente a soportes sucede tras el ataque nucleofílico de determinados aminoácidos expuestos hacia el exterior de la superficie de la enzima (principalmente lisina, a través de su grupo $\varepsilon$-amino) sobre grupos químicos reactivos de un soporte previamente funcionalizado (por ejemplo, soportes comerciales epoxidados como Eupergit ${ }^{\circledR}$, Sepabeads ${ }^{\circledR}$, Relizyme ${ }^{\circledR}$, etc.). Finalmente, el entrecruzamiento (también denominado reticulado) es una técnica de inmovilización donde la enzima es el propio soporte. Para ello, se emplean reactivos bifuncionales que originan uniones intermoleculares entre las moléculas de enzima. El agente reticulante más empleado es el glutaraldehído, el cual reacciona con las lisinas situadas en la superficie de distintas moléculas de enzima, originando enlaces covalentes (bases de Schiff) intermoleculares irreversibles. Aunque se han desarrollado y aplicado muchas técnicas de inmovilización a numerosas enzimas, se reconoce que no existe un método universal válido. No obstante, gracias a toda la información disponible, se podría seleccionar la técnica más adecuada para inmovilizar una enzima destinada a una aplicación industrial concreta.

\section{ENZIMAS EN MEDIOS NO CONVENCIONALES}

Aunque en principio pueda resultar sorprendente, las enzimas son capaces de retener su actividad catalítica en sistemas que contienen disolventes orgánicos ("Biocatálisis en medios no convencionales"). Este hecho no debería resultar extraño si tenemos en cuenta que muchas enzimas trabajan en ambientes hidrofóbicos en la Naturaleza (en emulsiones, o en presencia o unidas a una membrana). Las reacciones enzimáticas en sistemas con disolventes orgánicos presentan una serie de ventajas en comparación con las reacciones catalizadas normalmente en medios acuosos. Por una parte, el disolvente orgánico permite incrementar la solubilidad de aquellos sustratos que son hidrofóbicos. Adicionalmente, la recuperación de los productos de la reacción en aquellos disolventes de bajo punto de ebullición es más sencilla. Por otro lado, no hay posibilidad de que exista contaminación bacteriana. Finalmente, las hidrolasas presentan capacidad sintética en estos medios no convencionales (es decir, catalizan la reacción inversa a la hidrólisis), preservando su especificidad de sustrato, lo que resulta muy interesante a la hora de utilizar estos biocatalizadores en Síntesis Orgánica. En el caso de las enzimas empleadas en disolventes orgánicos anhidros, los biocatalizadores solo son activos si una "capa esencial" de agua recubre la estructura proteica, man- teniendo su integridad. Aquellos disolventes que son polares ( $y$, por tanto, miscibles con el agua) poseen mayor capacidad para sustraer ese agua esencial de la enzima y producen su desactivación. Por el contrario, los disolventes apolares no alteran la capa de agua esencial de la enzima, y esta permanece activa. Para conocer la polaridad del disolvente se recurre a su $\log P$, siendo $\mathrm{P}$ el coeficiente de partición del disolvente en un sistema compuesto por n-octanol y agua. En general, la actividad enzimática es baja en disolventes cuyo $\log P<2$, y alta si el $\log P>4$. Si la enzima fuera poco estable en un medio no convencional, se podría recurrir a estrategias de estabilización como la inmovilización covalente a soportes o el reticulado, la modificación química con cadenas de polietilénglicol, o la ingeniería de proteínas mediante mutagénesis o evolución dirigida. Recientemente, los líquidos iónicos (por ejemplo, el BMIM-BF ${ }_{4}$ ) han surgido como disolventes interesantes para llevar a cabo reacciones biocatalizadas, presentando ventajas de tipo medioambiental, en comparación con los disolventes orgánicos convencionales.

\section{NUEVOS BIOCATALIZADORES MEDIANTE MUTAGÉ- NESIS Y EVOLUCIÓN DIRIGIDA DE ENZIMAS}

Muchas enzimas aisladas a partir de fuentes naturales, pueden ser interesantes para un determinado proceso biotecnológico, pero sus propiedades normalmente no suelen ser las óptimas a nivel industrial. Además de los métodos de inmovilización descritos, existen otras técnicas que permiten aumentar la estabilidad de las enzimas, además de incrementar su actividad o incluso su especificidad de sustrato. Estas alternativas se basan en (1) la mutagénesis racional de residuos concretos del centro activo $u$ otras zonas de la estructura de la enzima; y (2) la evolución dirigida de enzimas. En el primer caso, se sabe que hay determinadas modificaciones que generan una rigidez conformacional (por ejemplo, la sustitución de un aminoácido por prolina, la sustitución de glicina por otro aminoácido, la introducción de cisteínas que generen puentes disulfuro intramoleculares), y cuyo resultado es un aumento en la estabilidad de la enzima y/o eficacia catalítica o cambios en la especificidad de sustrato. Un ejemplo es Lipolase ${ }^{\circledR}$, primera lipasa disponible comercialmente para su uso en detergentes. Inicialmente se obtenía a partir de la fermentación del hongo Thermomyces lanuginosus, pero los niveles de producción eran muy bajos. Mediante técnicas de ingeniería genética se consiguió clonar y producir esta enzima en Aspergillus oryzae, que es como se produce industrialmente en la actualidad. Además, mediante 
mutagénesis dirigida se ha conseguido obtener mutantes con nuevas propiedades, como Lipolase Ultra ${ }^{\circledR}$ de Novozymes, capaz de llevar a cabo la reacción a temperaturas inferiores a $20^{\circ} \mathrm{C}$. Para ello el $\mathrm{Asp}^{96}$ se cambió por una leucina. Con este cambio se reduce la fuerza de repulsión electrostática entre la enzima y el soporte sólido donde se encuentra el sustrato, por ejemplo la fibra textil, haciendo que el centro activo sea más hidrofóbico, lo que aumenta la afinidad de la enzima por el sustrato lipídico presente en el tejido. En el segundo caso, la evolución dirigida in vitro intenta emular la evolución darwiniana en el tubo de ensayo, generando una diversidad enorme de enzimas mutantes, las cuales posteriormente deben ser analizadas con ayuda de métodos de cribado de alto rendimiento (high-throughput screening) con el fin de seleccionar aquellas enzimas con propiedades mejoradas. Un ejemplo es la obtención de la subtilisina S41 de la cepa psicrofílica Bacillus TA41 con elevada eficacia catalítica a bajas temperaturas para su uso en detergentes.

\section{APLICACIONES DE LAS ENZIMAS EN LA INDUSTRIA ALIMENTARIA}

En la industria alimentaria, las enzimas (tanto libres como inmovilizadas) se utilizan para recuperar subproductos, facilitar la fabricación, mejorar el aroma, y/o estabilizar la calidad de los alimentos. Las enzimas industriales más utilizadas son carbohidrasas, proteasas y lipasas, aunque también se emplean oxidorreductasas e isomerasas. La mayoría de estas enzimas son de origen microbiano, y solo unas pocas proceden de animales o vegetales superiores. Por ejemplo, la obtención industrial de glucosa se produce fundamentalmente mediante hidrólisis enzimática del almidón de maíz, aunque en determinados países se recurre a otras fuentes vegetales como el trigo, la tapioca, o el arroz. Para la fabricación de jarabes ricos en glucosa, se utilizan enzimas inmovilizadas de Bacillus y/o Aspergillus en dos etapas: (1) $\alpha$-amilasas capaces de hidrolizar los enlaces glicosídicos $\alpha-(1,4)$ de la amilosa del almidón para dar lugar a dextrinas y maltosa, en un proceso denominado licuefacción; y (2) glucoamilasas que consiguen la hidrólisis total del almidón en glucosa si se emplean en combinación con enzimas que son capaces de hidrolizar los enlaces $\alpha-(1,6)$ de las ramificaciones de la amilopectina, en un proceso denominado sacarificación. Los jarabes ricos en glucosa se emplean en la preparación de bebidas refrescantes y caramelos, en panadería y en destilerías, mientras que los jarabes ricos en fructosa se utilizan en bebidas refrescantes, conservas, salsas, yogures y frutas enlatadas, debido a su mayor poder edulcorante. En la fabricación de estos jarabes ricos en fructosa, se recurre a una glucosa isomerasa inmovilizada, enzima que cataliza la conversión de la glucosa en fructosa, y que ha sido aislada de bacterias (Bacillus) o actinomicetos (Actinoplanes y Streptomyces). En países donde se cultiva caña de azúcar, la sacarosa se puede convertir en glucosa y fructosa utilizando la enzima invertasa, generalmente procedente de la levadura Saccharomyces cerevisiae. El producto obtenido de la hidrólisis enzimática de la sacarosa se denomina "azúcar invertido", y es más estable que los jarabes de glucosa ya que no suele cristalizar. Se utiliza en pastelería para mantener la humedad, y también evitar la aparición de paladar arenoso en las mermeladas. Otra aplicación de la Biocatálisis en la industria alimentaria es la preparación de leche sin lactosa, un producto de consumo cada vez más habitual en los supermercados. La intolerancia a la lactosa es una enfermedad hereditaria, muy prevalente en países como la India o Egipto (76\% de la población), que cursa con episodios diarreicos y otros trastornos intestinales tras la ingesta de leche y otros derivados lácteos. En la industria, la eliminación de este azúcar se puede lograr mediante el tratamiento de la leche con 6-galactosidasa (procedente generalmente de levaduras del género Kluyveromyces) inmovilizada. Dicho proceso es interesante en la preparación de helados, ya que la lactosa tiende a cristalizar a temperaturas bajas. Las pectinas y la celulosa son polímeros que se liberan durante el prensado de verduras y frutas en la fabricación de zumos, siendo responsables de su turbidez y viscosidad. En la industria alimentaria, los procesos de clarificación de zumos incluyen el empleo de enzimas fúngicas como pectinesterasas, pectinliasas, hemicelulasas y celulasas, que permiten la obtención de zumos menos viscosos, más concentrados y estables. Los métodos tradicionales de elaboración del pan se han basado en la presencia de enzimas endógenas en la masa que se obtiene a partir de la mezcla de la harina con el agua. Hoy en día, las harinas se suplementan con $\alpha$-amilasas, proteasas y lipasas, enzimas que mejoran el proceso de fabricación del pan, su sabor, textura de la masa y calidad de la corteza. Otro ejemplo es la quimosina o renina del cuajo de ternera, uno de los pocos ejemplos de enzimas de origen animal con aplicación industrial. Se emplea en la fabricación del queso para cuajar la leche, al ser capaz de hidrolizar de forma específica el enlace peptídico entre $\mathrm{Phe}^{105}$ y $\mathrm{Met}^{106}$ de la caseína $k$. Como alternativa al cuajo de ternera, existen enzimas microbianas con la misma especificidad de sustrato como 
las mucorpepsinas de Mucor pusillus o Mucor miehei, y la endotiapepsina de Endothia parasítica. También se pueden añadir lipasas microbianas que hidrolizan los triglicéridos para liberar ácidos grasos que pueden convertirse en las distintas cetonas responsables del sabor y aroma característicos de la leche de procedencia. Como ejemplo de enzima de origen vegetal, cabe destacar la papaína procedente de las hojas y del fruto sin madurar de la papaya (Carica papaya), utilizada en la industria alimentaria para ablandar la carne. Esta enzima es particularmente útil al ser estable al calor, por lo que su acción continúa durante las primeras etapas del cocinado. Finalmente, hay un grupo amplio de enzimas que se utilizan para mejorar las características organolépticas de ciertos alimentos y bebidas después de su procesado. Por ejemplo, las lacasas se emplean para oxidar los polifenoles en el mosto o en el té (responsables de su sabor y color posterior); las tanasas permiten eliminar el elevado contenido en taninos (responsables de la aparición de precipitados) en zumos, cervezas, vino y otras bebidas; y la narangi- nasa permite hidrolizar aquellos compuestos amargos de algunos cítricos como el pomelo, sin que se pierda el color natural de la fruta. Los electrodos enzimáticos o biosensores fabricados con enzimas inmovilizadas también son muy útiles en el control de calidad de muchos alimentos, y su utilidad se ha extendido a otras áreas como el control medioambiental (para medir concentración de metales tóxicos, pesticidas, herbicidas) o en el diagnóstico de enfermedades.

\section{APLICACIONES DE LAS ENZIMAS EN LA INDUSTRIA QUÍMICA Y FARMACÉUTICA}

La utilización de biocatalizadores en la industria química y farmacéutica es cada vez más frecuente, debido a las ventajas que presentan las enzimas frente a los catalizadores inorgánicos, comentadas anteriormente. La utilización de enzimas en estas industrias está enfocada principalmente a: (1) la obtención de precursores de fármacos (APIs) y semisíntesis de fármacos; y (2) la resolución enzimática de mezclas racémicas.

Figura 2. Semisíntesis del paclitaxel $\left(\operatorname{Taxol}^{\circledR}\right)$ mediante métodos enzimáticos

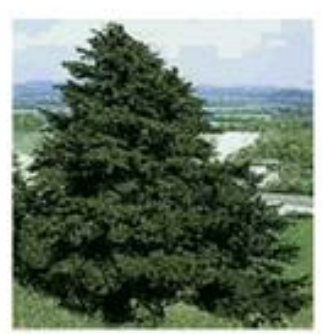

PRIMER PASO: Obtención de 10-DAB

SEGUNDO PASO: Obtención de la cadena lateral del paclitaxel
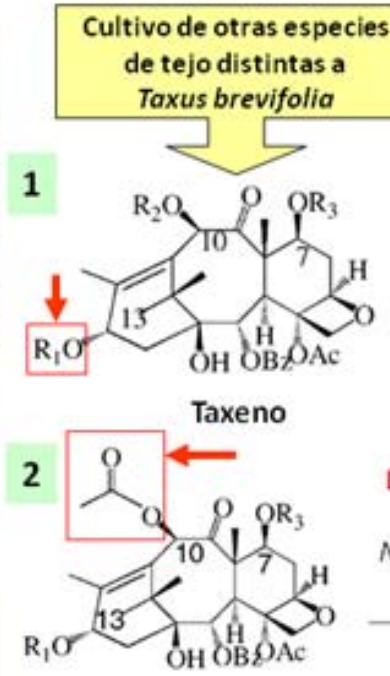

Baccatina III
Obtención de materia prima (hojas, corteza) para aislar taxenos

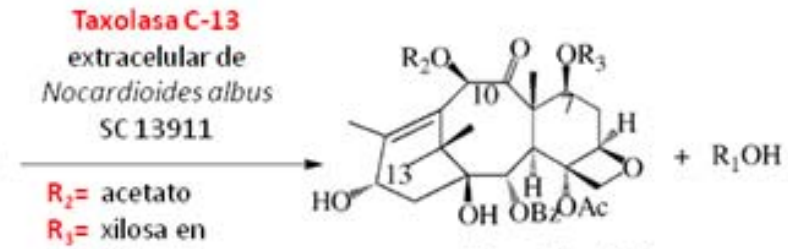

xiloxil-taxano

Baccatina III

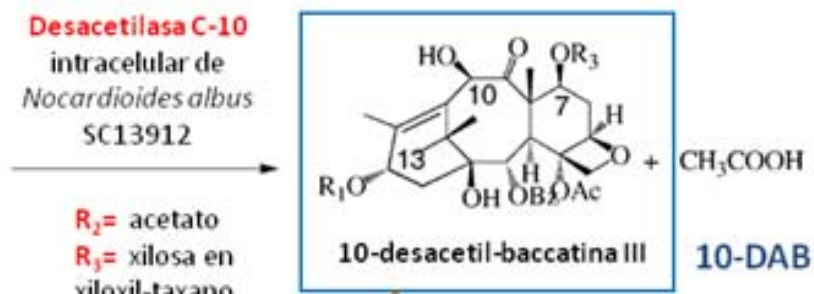

Desacetilasa C-10 intracelular de cardioides albus $R_{2}=$ acetato xiloxil-taxano<smiles>CCOC(=O)C(Cl)C(=O)c1ccccc1</smiles>

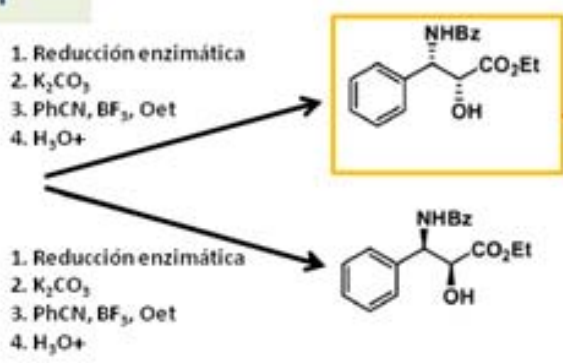<smiles>O=C(NC(c1ccccc1)C(O)C(=O)Cl)c1ccccc1</smiles>

TERCER PASO: Semisintesis del taxol Paclitaxel
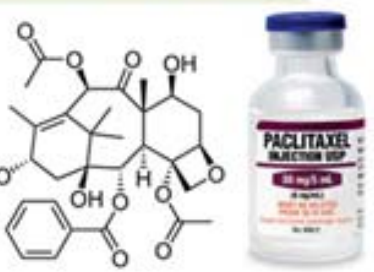
En el primer caso, las empresas farmacéuticas suelen acudir a métodos de semisíntesis de fármacos de origen natural, en su mayor parte moléculas complejas con un gran número de centros quirales, debido a la escasez de la fuente natural del fármaco o la complejidad del proceso de Síntesis Orgánica. Un ejemplo es la síntesis del paclitaxel $\left(\operatorname{Taxol}^{\circledR}\right)$, agente antimitótico empleado para el tratamiento de cáncer de pulmón, ovario, mama y formas avanzadas del sarcoma de Kaposi, y aprobado por la FAD en 1998. El paclitaxel tiene su origen en el "tejo del Pacífico" (Taxus brevifolia), y su purificación a partir de la fuente vegetal es complicada y con rendimiento final es muy bajo. De hecho, es necesario procesar 9 toneladas de corteza obtenida de 3.000 tejos para conseguir solamente $1 \mathrm{~kg}$ de paclitaxel. No es de extrañar que se hayan establecido métodos de semisíntesis de este compuesto a partir de otras fuentes vegetales de taxenos. La semisíntesis del paclitaxel se basa en la unión de dos precursores, el 10-DAB y la cadena C-13, que se obtienen a través de reacciones biocatalizadas por enzimas (Figura 2). Otro ejemplo de Biocatálisis en la industria de antibióticos, sería la utilización de enzimas para la obtención del ácido 6-aminopenicilánico (6-APA) y ácido 7-amino cefalosporánico (7-ACA), precursores de antibióticos $\beta$-lactámicos semisintéticos con propiedades mejoradas (Figura 3). Otra aplicación de las enzimas en Síntesis Orgánica y Farmacéutica es la resolución de mezclas racémicas con el fin de obtener de los isómeros o enantiómeros puros, difíciles de separar por los métodos químicos clásicos. La preparación de isómeros puros es de vital importancia en el caso de aquellas moléculas de fármacos que contengan algún carbono asimétrico, ya que actualmente es obligatorio realizar los ensayos clínicos pertinentes con ambos isómeros y con la mezcla racémica, de acuerdo a las directrices de organismos internacionales como la Food and Drug Administration (FDA) o la Agencia Europea del Medicamento (EMEA) antes de aprobar su comercialización. En general, solamente uno de los isómeros ("eutómero") es el que interacciona con su diana terapéutica (centro activo de una enzima, un receptor) para producir el efecto farmacológico, mientras que el otro isómero ("distómero") es inactivo o apenas presenta actividad en el mejor de los casos, ya que incluso puede ser tóxico. De hecho, el tristemente conocido caso de la talidomida es un ejemplo de fármaco cuyo distómero tiene efecto teratogénico. Este fármaco fue comercializado entre los años 1958 y 1963 como sedante y calmante de las náuseas durante los tres primeros meses de embarazo, y provocó miles de nacimientos de bebés afectados de focomelia, una anomalía congé- nita caracterizada por la carencia o excesiva cortedad de las extremidades. En resumen, la Biocatálisis se ha establecido como un recurso adicional en la síntesis de fármacos, sino también de otros productos químicos como herbicidas, insecticidas, edulcorantes, etc. Los biocatalizadores más empleados en la industria química y farmacéutica abarcan diferentes clases de enzimas como las hidrolasas (lipasas, acilasas, proteasas), las liasas (aldolasas), o las oxidorreductasas (oxidasas, oxigenasas, deshidrogenasas).

La mayoría de estas enzimas se suelen emplear como biocatalizadores inmovilizados, tanto en medios acuosos tamponados como en medios no convencionales, permitiendo su estabilización en las condiciones de reacción y su reciclado.

\section{OTRAS APLICACIONES INDUSTRIALES DE LAS ENZIMAS}

Las enzimas también tienen aplicación en la industria textil, peletera, papelera, y de fabricación de biocombustibles y bioplásticos. Por ejemplo, el efecto "lavado a la piedra" de prendas vaqueras se puede conseguir mediante métodos mecánicos abrasivos, o por acción de diferentes celulasas microbianas. Las celulasas contribuyen a suavizar tejidos de algodón, y pueden estar en la composición de algunos detergentes. En este sentido, prácticamente todos los detergentes comunes contienen lipasas o proteasas que contribuyen a la eliminación de manchas de grasa y/o restos de comida (o sangre).

Asimismo, los procesos de blanqueamiento de los vaqueros en la industria textil, y del papel en la industria papelera se logran mediante la utilización de las lacasas, un grupo de enzimas que catalizan la oxidación de compuestos fenólicos, reacción que también tiene su utilidad en descontaminación ambiental. El tratamiento de las pieles en la industria peletera incluye procesos de depilación enzimática con proteasas, y eliminación de grasa que facilita el teñido homogéneo de la piel. Respecto a los biocombustibles, el "bioetanol" procede de la fermentación de la glucosa obtenida previamente por hidrólisis enzimática del almidón (normalmente de maíz, aunque presente en otras fuentes vegetales), proceso biocatalizado por distintas enzimas como las amilasas, las glucoamilasas y las pululanasas. En cambio, el "biodiesel" se obtiene mediante transesterificación con metanol de los triglicéridos procedentes de distintos aceites vegetales, reacción que puede ser catalizada por distintas lipasas microbianas. Los productos de esta reacción son el glicerol, y los ésteres metílicos de los ácidos grasos que constituyen el "biodiesel" (Figura 4). Con 
Figura 3. Enzimas en la producción industrial de antibióticos $\beta$-lactámicos semisintéticos

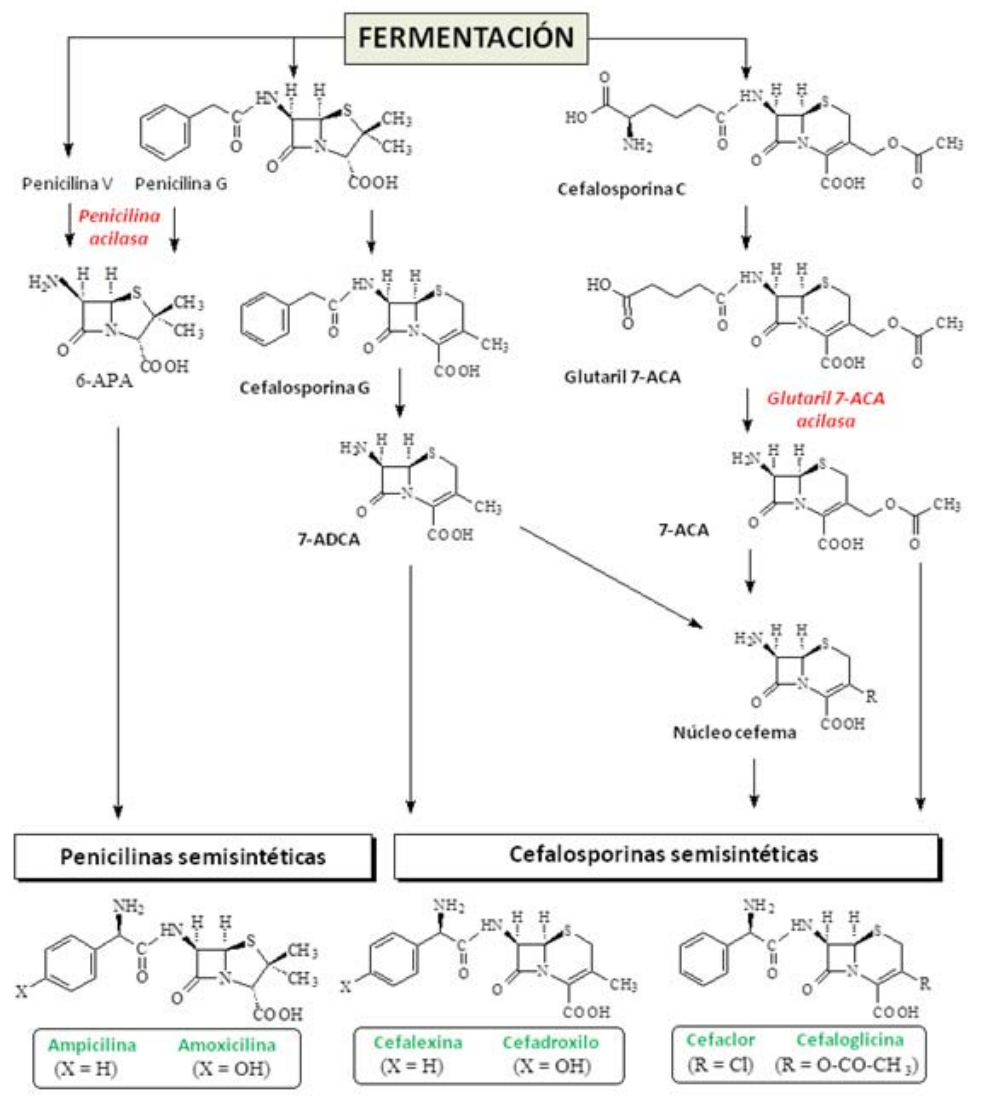

Figura 4. Obtención de biodiesel mediante métodos enzimáticos

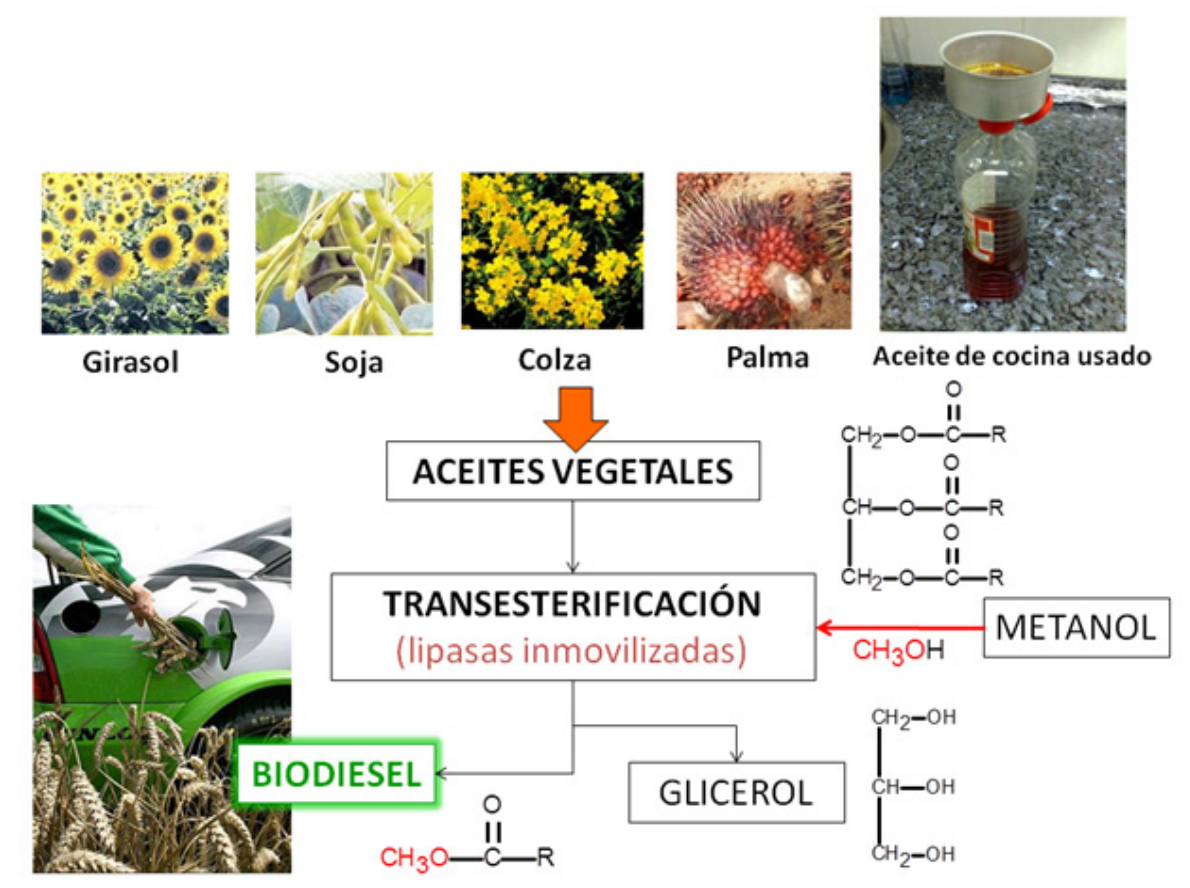


respecto a los bioplásticos, las denominadas polihidroxialcanoato sintasas y despolimerasas se perfilan como nuevos biocatalizadores para la obtención y degradación de polihidroxialcanoatos (PHA), biopolímeros con propiedades similares a los plásticos derivados del petróleo y cuya hidrólisis enzimática proporciona intermediarios quirales para la síntesis de compuestos de alto valor añadido como vitaminas, antibióticos, antihipertensivos, etc.

\section{FUTURO DE LA BIOCATÁLISIS}

El auge indiscutible de la Biocatálisis se debe a los grandes avances científicos que se han sucedido en los últimos años en diferentes áreas como la Bioquímica, la Ingeniería Genética y la Microbiología. Con la tecnología del DNA recombinante se ha logrado la expresión de enzimas en grandes cantidades, lo que ha favorecido una disminución de su precio. Por otra parte, las técnicas de mutagénesis y evolución dirigida han permitido la obtención de nuevos biocatalizadores que presentan un aumento de actividad, estabilidad y/o especificidad respecto a sus respectivas enzimas nativas. Por otro lado, las numerosas técnicas de inmovilización de enzimas han logrado facilitar la posterior reutilización de los biocatalizadores, así como mejorar su estabilidad a distintos valores de $\mathrm{pH}$ y temperatura, lo que ha abaratado los costes de muchos procesos biocatalizados. Asimismo, la biocatálisis en medios no convencionales ha posibilitado la realización de reacciones enzimáticas con muchos sustratos poco solubles o insolubles en agua y, de esta manera, se ha ampliado el campo de aplicación de las enzimas en la síntesis de muchos compuestos orgánicos como alternativa a la síntesis química tradicional. Se puede decir que el futuro de la Biocatálisis es prometedor, y que seremos testigos de un número cada vez mayor de aplicaciones de las enzimas en Biotecnología.

\section{LA BIOCATÁLISIS EN ESPAÑA}

En España existe un número apreciable de grupos de investigación, tanto en el Consejo Superior de Investigaciones Científicas (CSIC) como en la Universidad, que se dedican al estudio y aplicación de las enzimas en Biotecnología. El primer grupo español de Biocatálisis es el fundado por el Dr. Antonio BaIlesteros en el año 1969 en el Instituto de Química Física Rocasolano (IQFR-CSIC), que posteriormente se trasladó al Instituto de Catálisis y Petroleoquímica (ICP-CSIC). En la actualidad, el ICP-CSIC consta de varios grupos cuyas líneas de investigación están relacionadas con este campo, entre los que destacan el grupo de Biocatálisis Aplicada liderado por el Dr. Francisco Plou; el grupo de Evolución Dirigida de Enzimas cuyo investigador principal es el Dr. Miguel Alcalde; el grupo de Ingeniería Enzimática dirigido por el Dr. José Manuel Guisán, pionero en el campo de inmovilización de enzimas; y el grupo de Optimización de Biocatalizadores y Procesos Enzimáticos, recientemente creado por el Dr. Roberto Fernández Lafuente. Con el fin de evitar ser demasiado exhaustivo, se han omitido otros grupos más reducidos en el ICP-CSIC, no por ello menos importantes. En otros centros del CSIC, se encuentran otros grupos relevantes en el campo de la Biocatálisis, entre los cuales destacan el del Dr. Eduardo García-Junceda en el Instituto de Química Orgánica General (IOQGCSIC), el del Dr. Pere Clapés en el Instituto de Química Avanzada de Cataluña (IQAC-CSIC) y los grupos del Dr. Ángel Martínez y Ma Jesús Martínez del CIBCSIC. En el año 1989, el Dr. José Vicente Sinisterra estableció su grupo de Biotransformaciones en el Departamento de Química Orgánica y Farmacéutica de la Facultad de Farmacia de la Universidad Complutense de Madrid, cediendo el testigo de su actividad investigadora al Dr. Andrés Alcántara y a la Dra. María José Hernáiz. Dentro de la Universidad española existen muchos otros grupos que han encontrado en las aplicaciones biotecnológicas de las enzimas el fundamento de sus líneas de investigación. Es el caso de los grupos liderados por el Dr. Pedro Lozano (Universidad de Murcia) especializado en Biocatálisis en medios no convencionales; el Dr. Francisco Valero (Universidad Autónoma de Barcelona), el Dr. Vicente Gotor (Universidad de Oviedo), el Dr. Juan Luis Serra (Universidad del País Vasco), el Dr. Jesús Sanz (Universidad Miguel Hernández de Elche), la Dra. María Fernández-Lobato y el Dr. José Berenguer (Universidad Autónoma de Madrid).

Por último, los autores querrían destacar brevemente la trayectoria del Grupo de Biotecnología Enzimática del Departamento de Bioquímica y Biología Molecular I de la Facultad de Ciencias Biológicas de la Universidad Complutense de Madrid, del que forman parte. Dicho grupo comenzó su andadura en el año 1983 con el estudio del complejo enzimático celulasa aislado del hongo Trichoderma reesei, con la finalidad de optimizar su producción y abordar su caracterización. Más tarde el grupo orientó sus esfuerzos hacia el estudio de las enzimas implicadas en la fabricación de antibióticos $\beta$-lactámicos semisintéticos (la penicilina acilasa de Streptomyces lavendulae, y las D-aminoácido oxidasas de Rhodotorula gracilis 
y Trigonopsis variabilis) y antifúngicos semisintéticos (acuelacina A acilasa de Actinoplanes utahensis). Más recientemente, el grupo, se dedica al estudio de otras enzimas microbianas de interés biotecnológico como son: (1) las 2-desoxirribosil transferasas (NDTs) de distintos microorganismos, tanto mesófilos (Lactobacillus reuteri) como psicrófilos (Desulfotalea psychrophila y Bacillus psychrosaccharolyticus), útiles en la síntesis de análogos de nucleósidos de interés terapéutico; y (2) las poli-hidroxialcanoato despolimerasas de Streptomyces (S. exfoliatus y S. ascomycinicus) involucradas en la degradación de bioplásticos y producción de ácidos $(R)$-3-hidroxialcanoicos. En la actualidad, el grupo emplea prácticamente todas las metodologías de la Biotecnología Enzimática: producción de las enzimas mediante procesos fermentativos, su purificación y caracterización (funcional y estructural), incremento de su producción fermen- tativa mediante cepas recombinantes obtenidas tras la clonación del gen correspondiente, modificación de aminoácidos del centro activo mediante mutagénesis dirigida, optimización de biocatalizadores mediante evolución dirigida, estudio de la funcionalidad enzimática en medios no convencionales, inmovilización mediante distintas estrategias, etc. Cabe destacar, que el grupo de Biotecnología Enzimática de la UCM ha sido además pionero en la enseñanza de la Biotecnología en la Universidad española. En el año 1972, se impartió por vez primera la asignatura "Bioquímica Industrial", y en años sucesivos y hasta la actualidad, se ha venido desarrollando la docencia de las asignaturas de "Procesos Biotecnológicos", "Bioquímica Industrial" y "Biotecnología Clínica y Farmacéutica" así como de "Enzimología" en las titulaciones de Licenciatura y Grado de Biología, Química, Bioquímica e Ingeniería Química.

\section{BIBLIOGRAFÍA}

Aehle, W. (ed.) (2007). Enzymes in industry. Production and applications. Weinheim: Wiley-VCH. http://dx.doi. org/10.1002/9783527617098

Arroyo, M. (2001).Tecnología enzimática aplicada. Madrid: Editorial de la Universidad Complutense.

Bommarius, A. S. y Riebel-Bommarius, B.R. (2004). Biocatalysis: Fundamentals and Applications. Weinheim: Wiley-VCH. http://dx.doi.org/10.1002/3527602364

Bornscheuer, U. T., Huisman, G. W., Kazlauskas, R. J., Lutz, S., Moore, J. C. y Robins, K. (2012). Engineering the third wave of biocatalysis. Nature, 485, pp. 185 194. http://dx.doi.org/10.1038/nature11117

Buchholz, K., Kasche, V. y Bornscheuer, U.T. (2005). Biocatalysts and enzyme technology. Weinheim: Wiley-VCH.

Cao, L. (2005). Carrier-bound immobilized enzymes: principles, application and design. Weinheim: Wiley-VCH. http:// dx.doi.org/10.1002/3527607668

Carrea, G. y Riva, S. (eds.) (2008). Organic synthesis with enzymes in non-aqueous media. Weinheim: Wiley-VCH. http:// dx.doi.org/10.1002/9783527621729

Davids, T., Schmidt, M., Boettcher, D. y Bornscheuer, U.T. (2013). Strategies for the discovery and engineering of enzymes for biocatalysis. Current Opi- nion in Chemichal Biology, 17, pp. 215-220. http://dx.doi.org/10.1016/j. cbpa.2013.02.022

DiCosimo, R., McAuliffe, J., Poulose, A.J. y Bohlmann, G. (2013). Industrial use of immobilized enzymes. Chemichal Society Reviews, 42, pp.6437-6474. http:// dx.doi.org/10.1039/c3cs35506c

Kumar, A. y Singh, S. (2013). Directed evolution: tailoring biocatalysts for industrial applications. Critical Reviews in Biotechnology, 33, pp. 365-378. http://dx.doi. org/10.3109/07388551.2012.716810

Miyazaki, K; Wintrode, P. L., Grayling, R. A., Rubingh, D. N. y Arnold, F. H. (2000). Directed evolution study of temperature adaptation in a psychrophilic enzyme. Journal of Molecular Biology, 297, pp. 1015-1026. http://dx.doi.org/10.1006/ jmbi.2000.3612

Patel, R.N. (ed.) (2006). Biocatalysis in the pharmaceutical and biotechnology industries. Florida: CRC Press.

Polaina, J. y MacCabe, A. P. (eds.) (2007). Industrial enzymes: Structure, function and applications. Dordrecht: Springer. http:// dx.doi.org/10.1007/1-4020-5377-0

Pollard, D.J. y Woodley, J.M. (2007). Biocatalysis for pharmaceutical intermediates: the future is now. Trends in Biotechnology, 25, pp. 66-73. http://dx.doi. org/10.1016/j.tibtech.2006.12.005
Rastall, L. (ed.) (2007). Novel enzyme technology for food applications. Cambridge: Woodhead Publishing Limited. http:// dx.doi.org/10.1533/9781845693718

Sheldon, R.A. (2007). Enzyme immobilization: the quest for optimum performance. Advanced Synthesis \& Catalisis, 349, pp. 1289-1307. http://dx.doi. org/10.1002/adsc. 200700082

Sheldon, R. A. y van Pelt, S. (2013). Enzyme immobilisation in biocatalysis: why, what and how. Chemical Society Reviews, 42, pp. 6223-6235. http://dx.doi. org/10.1039/c3cs60075k

Turner, N.J. (2009). Directed evolution drives the next generation of biocatalysts. Nature Chemichal Biology, 5, pp. 568574. http://dx.doi.org/10.1038/nchembio. 203

Rantwijk, F. van y Sheldon, R.A. (2007). Biocatalysisin ionic liquids. Chemichal Reviews, 107, pp. 2757-2785.

Woodley, J.M. (2008). New opportunities for biocatalysis: making pharmaceutical processes greener. Trends in Biotechnology, 26, pp. 321-327. http://dx.doi. org/10.1016/j.tibtech.2008.03.004 